\title{
Conductivity and Dielectric Studies of Lithium Trifluoromethanesulfonate Doped Polyethylene Oxide-Graphene Oxide Blend Based Electrolytes
}

\author{
A. A. Azli, ${ }^{1}$ N. S. A. Manan, ${ }^{2}$ and M. F. Z. Kadir $^{3}$ \\ ${ }^{1}$ Institute of Graduate Studies, University of Malaya, 50603 Kuala Lumpur, Malaysia \\ ${ }^{2}$ Chemistry Department, Faculty of Science, University of Malaya, 50603 Kuala Lumpur, Malaysia \\ ${ }^{3}$ Centre for Foundation Studies in Science, University of Malaya, 50603 Kuala Lumpur, Malaysia \\ Correspondence should be addressed to M. F. Z. Kadir; mfzkadir@um.edu.my
}

Received 13 November 2014; Accepted 19 December 2014

Academic Editor: Kwangho Kim

Copyright (C) 2015 A. A. Azli et al. This is an open access article distributed under the Creative Commons Attribution License, which permits unrestricted use, distribution, and reproduction in any medium, provided the original work is properly cited.

\begin{abstract}
Series of polymer blend consisting of polyethylene oxide (PEO) and graphene oxide (GO) as co-host polymer were prepared using solution cast method. The most amorphous PEO-GO blend was obtained using $90 \mathrm{wt} . \%$ of PEO and $10 \mathrm{wt} . \%$ of GO as recorded by X-ray diffraction (XRD). Fourier transform infrared spectroscopy (FTIR) analysis proved the interaction between PEO, GO, lithium trifluoromethanesulfonate $\left(\mathrm{LiCF}_{3} \mathrm{SO}_{3}\right)$, and ethylene sulfite (ES). Incorporation of $25 \mathrm{wt}$ \% $\mathrm{LiCF}_{3} \mathrm{SO}_{3}$ into the PEO-GO blend increases the conductivity to $(3.84 \pm 0.83) \times 10^{-6} \mathrm{~S} \mathrm{~cm}^{-1}$. The conductivity starts to decrease when more than $25 \mathrm{wt} . \%$ salt is doped into the polymer blend. The addition of $1 \mathrm{wt} . \%$ ES into the polymer electrolyte has increased the conductivity to (1.73 \pm $0.05) \times 10^{-5} \mathrm{~S} \mathrm{~cm}^{-1}$. Dielectric studies show that all the electrolytes obey non-Debye behavior.
\end{abstract}

\section{Introduction}

Polymer electrolytes are an important component of many electrochemical devices such as lithium batteries, capacitors, fuel cells, and solar cells. Armand et al. [1] first proposed the use of polyethylene oxide (PEO) and alkali salts system as solid polymer electrolytes (SPE) for lithium batteries, which immediately spurred an enormous amount of research worldwide. Application of SPE especially in electrochemical devices offers advantages in terms of ease of fabrication as thin-film materials, high reliability without leakage problem of liquid electrolytes, and higher temperatures of operation and miniaturization to ensure high energy density [2]. Despite its advantages, the low ionic conductivity of SPE at room temperature often limits their applications [3].

PEO is a widely used film-forming polymer with high tensile strength and flexibility $[4,5]$. PEO also exhibits many other useful properties such as chemical stability, ease of electrolyte fabrication, and excellent complexation with many ionic salts $[6,7]$. However, most PEO based polymer electrolytes have low conductivity due to its semicrystalline polymer nature in which, below the melting temperature of PEO at $330 \mathrm{~K}$, the polymer may consist of both lamellar crystals and amorphous regions, as well as intermediate regions at the crystal/amorphous interphase [8]. Crystalline polymer electrolytes have long been considered as insulators while ionic conductivity is confined exclusively to the amorphous state [9]. The ion migration in SPE is believed to occur predominantly in the amorphous rich phase; thus reducing crystallinity of PEO by blending PEO with other materials as a cohost polymer increases the conductivity of PEO based SPE.

Blend polymer of PEO with carbon materials can be considered as new perspective for electrochemical applications, especially for the storage of energy because the existence of different carbon allotropes (graphite, diamond, and fullerenes/nanotubes), various microtextures (more or less ordered) owing to the degree of graphitization, and a rich variety of dimensionality from 0 to $3 \mathrm{D}$ and ability for existence under different forms (from powders to fibres, foams, fabrics, and composites) indicate that carbon is 
a very attractive material to explore [10]. Graphene oxide (GO) is a highly oxygenated, hydrophilic layered material derived from graphite oxide resulting from oxidation of graphite by strong oxidising agents. Under the application of external energy, such as from ultrasonic vibration or thermal shock, three-dimensional graphite oxide can be exfoliated into two-dimensional graphite oxide nanosheets of single layer graphite oxide $[11,12]$. Graphite oxide nanosheets can be as thin as a one carbon layer and can then be described as GO nanosheets [13]. Reinforcement of nanometer sized materials may enhance most properties of polymer blend if they are well dispersed in the matrix polymer [14]. Other interesting features of GO are that it can be chemically functionalized and modified for the preparation of polymerbased composite materials and it is also precursor materials for preparing graphene nanosheets in large quantity for many other functional applications such as secondary batteries, ionic conductors, and supercapacitors $[15,16]$.

Incorporating appropriate salts into the PEO-GO host polymer matrix provides charge carriers to the polymer matrix in order to increase the ionic conductivity of the system. High molecular weight PEO based polymer electrolytes containing lithium salts are of particular interest because of their easy formation of complexes with lithium salts and high mobility of charge carriers particularly lithium trifluoromethanesulfonate $\left(\mathrm{LiCF}_{3} \mathrm{SO}_{3}\right)$ because the ionic conduction of $\mathrm{LiCF}_{3} \mathrm{SO}_{3}$ salt is ambipolar, which has lower Columbic potential and possesses higher segmental mobility of polymer chains $[6,17,18]$. Many studies on PEO-lithium salt system have reported that doping salt into the system has increased conductivity significantly $[6,18,19]$. The major drawback of these PEO-Li electrolyte systems for SPE is that they tend to crystallize at room temperatures resulting in low ionic conductivity $[20,21]$. Plasticization is one of the common ways of reducing crystallinity and also increasing the amorphous phase content of polymer electrolytes. Previous work has reported that the use of ethylene sulfite (ES) as plasticizer increased the room temperature conductivity to the order of $\sim 10^{-4} \mathrm{~s} \mathrm{~cm}^{-1}$ on PEO-chitosan blend polymer system [22]. ES has dielectric constant, $\epsilon$ of 39.6, which is higher than other common plasticizers, that is, dimethylacetamide $(\epsilon=$ $37.8)$ and diethyl carbonate $(\epsilon=2.82)$. Increase in electrolytes conductivity has been reported with incorporation of plasticizer with higher dielectric constant [5]. Besides, ES also has low melting point $\left(-17^{\circ} \mathrm{C}\right)$ which can ensure the plasticizer molecules will not solidify at room temperature which may limit the ion mobility [23]. The feasibility of ES in improving conductivity of the PEO based SPE can be investigated further and small loadings of ES contents minimize deterioration of the mechanical properties and the potential stability of the polymer films with the addition of plasticizers [24].

In this work, we prepare salted and plasticized SPE systems based on PEO-GO polymer blend doped with $\mathrm{LiCF}_{3} \mathrm{SO}_{3}$ as doping salt; meanwhile ES is reinforced as plasticizer in order to enhance the conductivity. The conductivity and dielectric properties of the electrolytes will be discussed.

\section{Materials and Methods}

2.1. Preparation of the Graphene Oxide (GO). GO nanosheets were prepared by a modified Hummers method [25]. Any extra acids and salts were removed through washing process using distilled water (DI). Mild sonication was applied to the suspension for about $10 \mathrm{~min}$ to exfoliate graphite oxide that still remains in the GO suspension. Finally, GO suspension was put into the oven for 48 hours at $60^{\circ} \mathrm{C}$ to discard water present, thus obtaining dark brown GO nanosheets.

2.2. Preparation and Characterization of Various PEO-GO Blend Films. Different weight percentages ( $x$ wt.\%) of GO nanosheets were mixed in $50 \mathrm{~mL}$ DI and homogenized using ultrasonicator XO-650D (Nanjing Xianou Instruments Co. Ltd.) for about $15 \mathrm{~min}$ at $50 \%$ crusher capacity. After the solutions cooled at room temperature, $(100-x)$ wt. $\%$ of PEO $\left(M_{v} \sim 300,000\right.$ containing $200-500$ ppm butylated hydroxytoluene as inhibitor, Aldrich Chemistry) was then added to the GO solutions. The mixtures were stirred until homogeneous solutions were obtained. All solutions were cast onto different plastic Petri dishes and left to dry at room temperature and then kept in a desiccator filled with silica gel desiccants for further drying.

$\mathrm{X}$-ray diffraction (XRD) measurements of the polymer blend films were carried out using a Siemens D5000 Xray diffractometer where X-rays of $1.54 \AA$ wavelengths were generated by a $\mathrm{Cu} \mathrm{K} \alpha$ source. The $2 \theta$ angle was varied from $5^{\circ}$ to $80^{\circ}$.

2.3. Preparation of Electrolytes. The polymer blend electrolyte system was prepared by homogenizing $10 \mathrm{wt} \%$ of GO nanosheets in $50 \mathrm{~mL}$ DI from total of $0.5 \mathrm{~g}$ polymer blend. After the solution was cooled to room temperature, $90 \mathrm{wt} . \%$ of PEO was added and stirred until homogenous solution was obtained. Prior to the preparation of the salted electrolytes, $\mathrm{LiCF}_{3} \mathrm{SO}_{3}$ (Aldrich Chemistry) was dried at $100^{\circ} \mathrm{C}$ for 1 hour to eliminate trace amounts of water in the material. Different amounts of $\mathrm{LiCF}_{3} \mathrm{SO}_{3}$ were added to the PEO-GO solutions and stirred until complete dissolution. For the preparation of plasticized system, different amounts of ES (Aldrich Chemistry) were added to the highest conducting salted electrolyte solutions and stirred until complete dissolution. All homogenous solutions were cast onto plastic Petri dishes and left to dry at room temperature for 2-3 days to form film. The dry films were then kept in desiccators filled with silica gel desiccants for several hours before being characterized to avoid any trace of moisture.

2.4. Characterization of Electrolytes. Impedance measurements were conducted using HIOKI 3532-50 LCR HiTESTER from room temperature to $373 \mathrm{~K}$ in the frequency range of $50 \mathrm{~Hz}$ to $5 \mathrm{MHz}$. The electrolyte films were sandwiched between two stainless steel electrodes of a conductivity holder with diameter of $1.9 \mathrm{~cm}$. The value of bulk resistance $\left(R_{b}\right)$ was determined from the Cole-Cole plots. Conductivity $(\sigma)$ was calculated using the following equation:

$$
\sigma=\frac{d}{R_{b} A}
$$




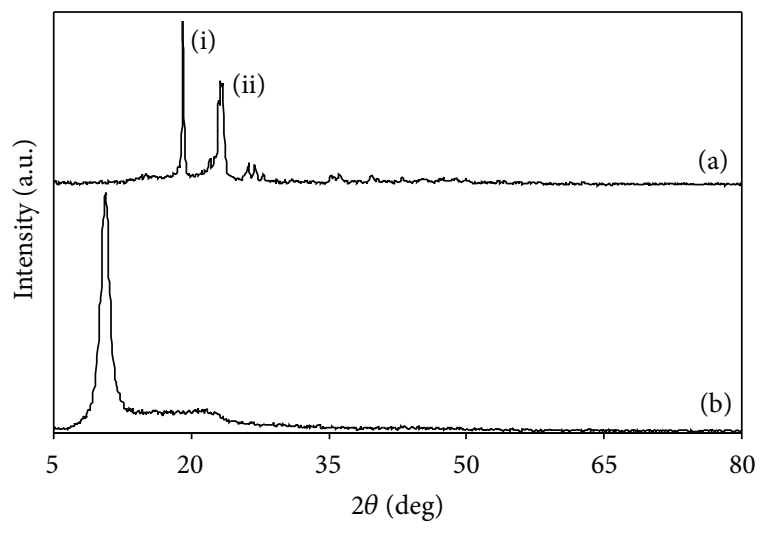

FIgURE 1: XRD pattern for (a) pure PEO and (b) pure GO.

where $d$ is the thickness of the electrolyte samples and $A$ is the electrode-electrolyte contact area. A digital thickness gauge (Mitutoyo Corp.) was employed to measure the thickness of the electrolytes.

The Fourier transform infrared spectroscopy (FTIR) studies were performed using attenuated total reflection infrared spectroscopy (ATR-IR) Perkin Elmer Spectrum 400 GladiATR in the wavenumber range of $400-4000 \mathrm{~cm}^{-1}$. The objective of FTIR was to confirm complexation between polymer and salt.

\section{Results and Discussion}

3.1. XRD of PEO-GO Blends. The choice of a proper ratio of polymer blend is crucial to its ability to serve as a polymer host in electrolytes because suitable ratio of polymer blend controls the reduction in crystallinity of the polymer blend. Qualitative identification of crystallinity structure can be made by comparing the position of XRD peaks and intensity of the peaks for polymer blends with standard patterns of pure material. Figure 1 shows XRD pattern for (a) pure PEO and (b) pure GO films. The maximum intensity peaks of pure PEO film were observed at (i) $2 \theta=19.1^{\circ}$ and at (ii) $2 \theta=23^{\circ}$. These two peaks of PEO also have been reported by Kumar et al. [26] at $2 \theta=19.36^{\circ}$ and at $2 \theta=23.72^{\circ}$ and other authors $[27,28]$. Several less intense peaks are exhibited around $2 \theta$ $=26.3^{\circ}, 27.0^{\circ}, 35.6^{\circ}, 36.4^{\circ}, 39.9^{\circ}$, and $43.1^{\circ}$. The sharp peaks indicate the crystalline phase of PEO, which originates from the ordering of polyether side chains because there is strong intermolecular interaction between PEO chains through the hydrogen bonding [26]. Meanwhile, a very intense and sharp peak of pure GO film was found to be at $2 \theta=10.7^{\circ}$ on Figure 1 . According to Mural et al. [29], XRD peak of graphite, that is, starting material of GO occurring at $2 \theta=26.46^{\circ}$, has shifted to lower angle at $2 \theta=9.5^{\circ}$ due to oxidative functionalization of graphitic structures.

Figure 2 shows the XRD pattern for different ratio (wt.\%) of PEO-GO films in comparison to the pure PEO film (100 wt.\% PEO) and pure GO film (100 wt.\% GO). Changes in peak position or peak shape can be seen consequently in Figure 2. The very sharp peak of $100 \mathrm{wt} \%$ GO shifts in

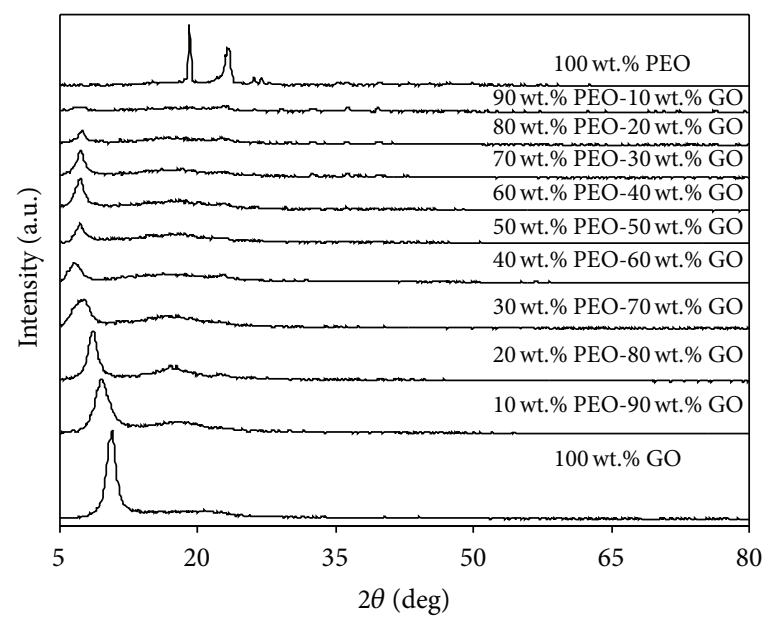

FIgure 2: XRD pattern for pure PEO (100 wt.\% PEO), pure GO (100 wt.\% GO), and different ratio (wt.\%) of PEO-GO blends.

the lower angle $2 \theta=9.8^{\circ}$ with the presence of $10 \mathrm{wt} . \%$ of PEO in the blend and the trend is similar for $20 \mathrm{wt} . \%$ of PEO $(2 \theta=$ $\left.8.7^{\circ}\right), 30 \mathrm{wt} . \%$ PEO $\left(2 \theta=7.8^{\circ}\right)$, and $40 \mathrm{wt} . \%$ of PEO $(2 \theta=$ $\left.6.8^{\circ}\right)$. At $50 \mathrm{wt} . \%$ PEO-50 wt.\% GO blend, GO peak has already shifted to slightly higher angle of $2 \theta=7.4^{\circ}$ and the trend of GO peak follows for up to $80 \mathrm{wt}$ \% PEO-20 wt.\% GO blend. The shift in high or lower angle for every different ratio proved that $\mathrm{PEO}$ and $\mathrm{GO}$ have been blended together. It was observed that, at $90 \mathrm{wt} . \%$ PEO-10 wt.\% GO blend, the peak shape of GO has become broad compared to others indicating that high intensity of GO peak has been lowered at this particular ratio. Throughout Figure 2, the peaks of PEO are not visible because those peaks have been superimposed by the maximum intensity of the GO peak. Since the relative intensities of $90 \mathrm{wt} . \%$ PEO-10 wt.\% GO crystalline peaks are decreased, it is chosen in this work as polymer host because less crystallinity or amorphous phase observed signifies disruption of the rigid bonding of the material which enables ion migration for ionic conductivity [9].

3.2. FTIR Analysis. The complexation between the materials was studied using FTIR technique. Figure 3 shows two regions of FTIR spectra in which Figure 3(a) represents $\mathrm{O}-\mathrm{H}$ band for pure $\mathrm{GO}$ while Figure 3(b) represents $\mathrm{C}-\mathrm{H}$ stretching for pure PEO. These two main characteristics for each material were compared to the $90 \mathrm{wt} . \%$ PEO-10 wt.\% GO blend which is selected based on XRD results. The FTIR spectra of the graphene oxide nanosheets show a broad absorption band at $3190 \mathrm{~cm}^{-1}$ due to the typical carbonyl and carboxyl groups present in the GO structure. Wang et al. [13] and Cao et al. [30] also have reported the presence of $\mathrm{O}-\mathrm{H}$ band in GO nanosheets near $3300 \mathrm{~cm}^{-1}$ and $3390 \mathrm{~cm}^{-1}$. Upon addition of $90 \mathrm{wt} . \%$ PEO through polymer blending, the O-H band has shifted to $3223 \mathrm{~cm}^{-1}$; meanwhile Figure 3(b) depicts the $\mathrm{C}-\mathrm{H}$ stretching mode for pure $\mathrm{PEO}$ at $2871 \mathrm{~cm}^{-1}$ also has shifted to $2877 \mathrm{~cm}^{-1}$ when $10 \mathrm{wt} . \% \mathrm{GO}$ was added to the polymer host. Alteration in wavenumber of $\mathrm{O}-\mathrm{H}$ band and 


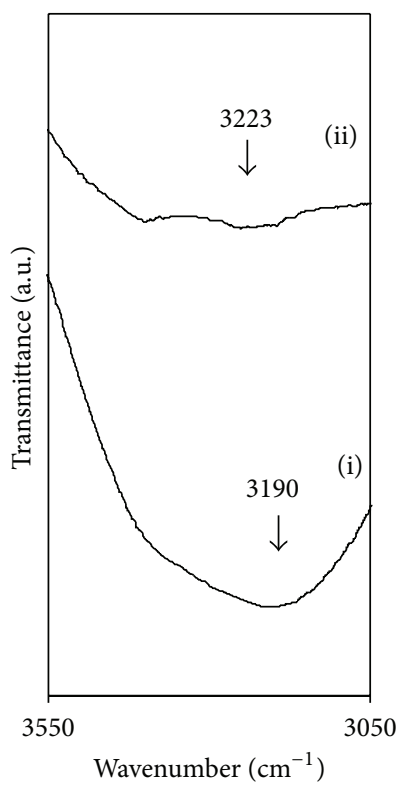

(a)

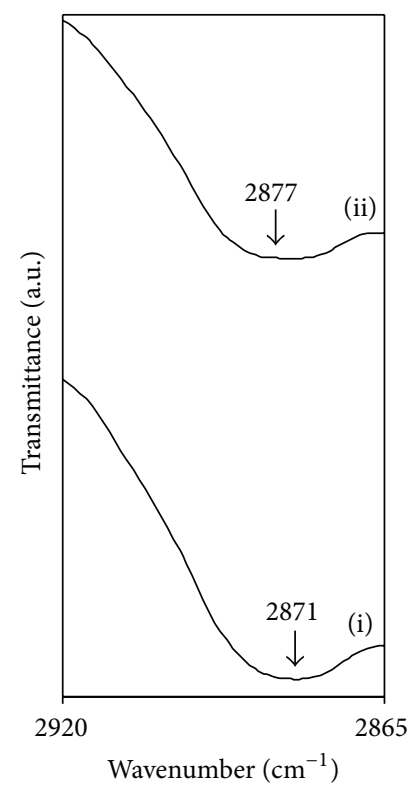

(b)

FIGURE 3: (a) FTIR spectra for (i) pure GO and (ii) 90 wt.\% PEO-10 wt.\% GO blend in the region of 3050-3550 $\mathrm{cm}^{-1}$. (b) FTIR spectra for (i) pure PEO and (ii) $90 \mathrm{wt} . \%$ PEO-10 wt.\% GO blend in the region of $2865-2920 \mathrm{~cm}^{-1}$.

$\mathrm{C}-\mathrm{H}$ stretching indicates that interaction in PEO-GO blend has occurred as reported by Mural et al. in [29].

Figure 4(a) shows the FTIR spectra of salted system of selected sample in the two main regions of $\mathrm{O}-\mathrm{H}$ band 3050$3650 \mathrm{~cm}^{-1}$ and also in the lower region around $630-650 \mathrm{~cm}^{-1}$ as presented in Figure 4(b). According to Starkey and Frech [31], band at $764 \mathrm{~cm}^{-1}$ is assigned to the $\delta_{s}\left(\mathrm{CF}_{3}\right)$ mode of the triflate ion $\left(\mathrm{CF}_{3}{ }^{-}\right)$. The appearance of a peak at $638 \mathrm{~cm}^{-1}$ for $5 \mathrm{wt} . \% \mathrm{LiCF}_{3} \mathrm{SO}_{3}$ could be attributed to triflate ion in the pure $\mathrm{LiCF}_{3} \mathrm{SO}_{3}$ salt as shown in Figure 4(b)(ii) because it is understood that the vibrational spectrum of triflate ion is very sensitive to its state of coordination, producing a series of different FTIR active bands as its environment changes [32]. It can been seen that, with increasing of the $\mathrm{LiCF}_{3} \mathrm{SO}_{3}$ content, intensities of the region around $635 \mathrm{~cm}^{-1}$ have become higher compared to the intensity of the peak for $5 \mathrm{wt} . \% \mathrm{LiCF}_{3} \mathrm{SO}_{3}$. For $\mathrm{O}-\mathrm{H}$ band, the wavenumber has shifted to the higher wavenumber values as depicted in Figure 4(a). Addition of $10 \mathrm{wt} . \% \mathrm{LiCF}_{3} \mathrm{SO}_{3}$ to the $90 \mathrm{wt} . \%$ PEO-10 wt.\% GO blend has shifted the value number from $3223 \mathrm{~cm}^{-1}$ to $3434 \mathrm{~cm}^{-1}$. Upon addition of $40 \mathrm{wt} . \%$ salt, the $\mathrm{O}-\mathrm{H}$ band shifts to lower wavenumber of $3468 \mathrm{~cm}^{-1}$ indicating a decrease in conductivity of the electrolyte. This result indicates that more salt aggregates have been formed which limit the conduction of ions. The increased wavenumber suggested that interaction in polymer blend with doping salt has occurred. Previous work by Karan et al. [33] proposed the coordination of the $\mathrm{Li}$ ions to the oxygen atoms of polymer backbone of $\mathrm{PEO}$ due to an increase in the glass transition temperature of the $\mathrm{PEO}-\mathrm{LiCF}_{3} \mathrm{SO}_{3}$ electrolytes with increasing Li salt content. Another work by Yadav et al. [34] on graphene oxide/carboxymethylcellulose/alginate
(GO/CMC/Alg) composite blends stated that there are hydrogen bonding-type interactions due to the occurrence of such shifting in the FTIR spectra. The hydrophilic oxygenated functional groups on the surface or at the edge of the GO sheets played a critical role in improving the compatibility between GO and the polymer matrix.

Figure 5 represents the FTIR spectra of selected sample from $\mathrm{PEO}-\mathrm{GO}-\mathrm{LiCF}_{3} \mathrm{SO}_{3}$-ES system in the region of $\mathrm{O}$ $\mathrm{H}$ band at $3400-3550 \mathrm{~cm}^{-1}$. From salted system, the $\mathrm{O}-\mathrm{H}$ band appearing at $3456 \mathrm{~cm}^{-1}$ has shifted to $3461 \mathrm{~cm}^{-1}$ with incorporation of $0.2 \mathrm{wt} . \% \mathrm{ES}$. The increase in wavenumber for each ES loading suggested that complexation of ES into the PEO-GO-LiCF $\mathrm{SO}_{3}$ electrolyte system occurred. From Figure 5(b), the $\mathrm{C}=\mathrm{O}$ band appearing at $1645 \mathrm{~cm}^{-1}$ shifts to lower wavenumber of $1641 \mathrm{~cm}^{-1}$ with incorporation of $0.2 \mathrm{wt} . \% \mathrm{ES}$ and the same peak can be observed for addition of 0.4 wt.\% ES-1.4 wt.\% ES in the polymer blend. The peak shape also has become broad and less intense compared to the peak without addition of ES. Bhatt and O'Dwyer [35] used computational studies to predict theoretical FTIR spectra on ES as additives in propylene carbonate-based Li-ion battery electrolyte in which wavenumber of $\mathrm{C}=\mathrm{O}$ of propylene carbonate increases as a result of a significant change in the bond length due to the interaction of $\mathrm{ES}$ on $\mathrm{C}=\mathrm{O}$ frequency. This demonstrates that changes in wavenumber could be possibly due to interaction between ES and PEO$\mathrm{GO}-\mathrm{LiCF}_{3} \mathrm{SO}_{3}$ system that alter the bond length of $\mathrm{C}=\mathrm{O}$ of the polymer host.

3.3. Conductivity Analysis. The effect of $\mathrm{LiCF}_{3} \mathrm{SO}_{3}$ concentration on room temperature conductivity is represented in Figure 6(a). The conductivity of pure PEO-GO film at 


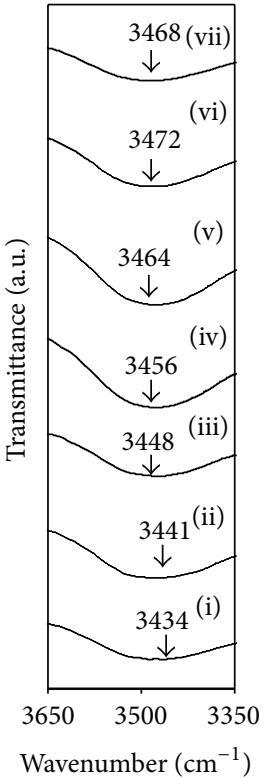

(a)

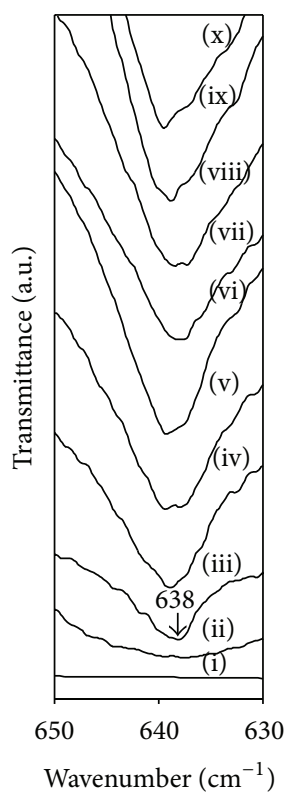

(b)

Figure 4: (a) FTIR spectra for 90 wt.\% PEO-10 wt.\% GO film with (i) 10 wt.\% $\mathrm{LiCF}_{3} \mathrm{SO}_{3}$, (ii) 15 wt.\% $\mathrm{LiCF}_{3} \mathrm{SO}_{3}$, (iii) 20 wt.\% $\mathrm{LiCF}_{3} \mathrm{SO}_{3}$, (iv) $25 \mathrm{wt} . \% \mathrm{LiCF}_{3} \mathrm{SO}_{3}$, (v) $30 \mathrm{wt} . \% \mathrm{LiCF}_{3} \mathrm{SO}_{3}$, (vi) $35 \mathrm{wt} . \% \mathrm{LiCF}_{3} \mathrm{SO}_{3}$, and (vii) $40 \mathrm{wt} . \% \mathrm{LiCF}_{3} \mathrm{SO}_{3}$ in the region of $3350-3650 \mathrm{~cm}^{-1}$. (b) FTIR spectra for (i) 90 wt.\% PEO-10 wt.\% GO film, (ii) pure $\mathrm{LiCF}_{3} \mathrm{SO}_{3}$ and PEO-GO blend with (iii) $5 \mathrm{wt} \% \mathrm{LiCF}_{3} \mathrm{SO}_{3}$, (iv) $10 \mathrm{wt} . \% \mathrm{LiCF}_{3} \mathrm{SO}_{3}$, (v) 15 wt. $\% \mathrm{LiCF}_{3} \mathrm{SO}_{3}$, (vi) 20 wt.\% $\mathrm{LiCF}_{3} \mathrm{SO}_{3}$, (vii) 25 wt. $\% \mathrm{LiCF}_{3} \mathrm{SO}_{3}$, (viii) $30 \mathrm{wt} . \% \mathrm{LiCF}_{3} \mathrm{SO}_{3}$, (ix) 35 wt. \% LiCF $\mathrm{SO}_{3}$, and (x) 40 wt.\% LiCF $3 \mathrm{SO}_{3}$ in the region of $630-650 \mathrm{~cm}^{-1}$.

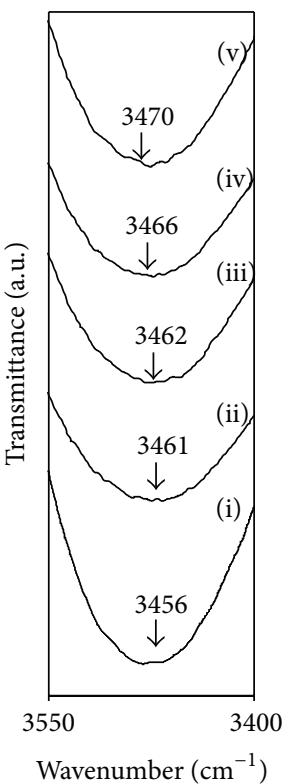

(a)

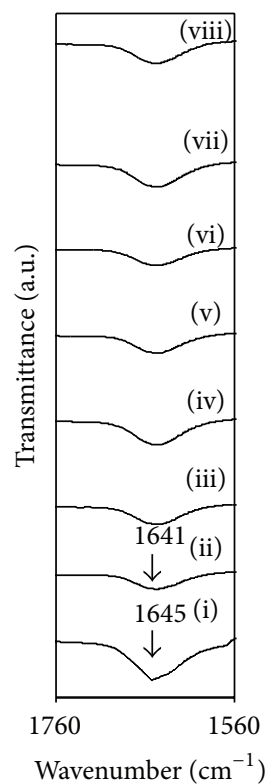

(b)

Figure 5: (a) FTIR spectra of (i) 90 wt.\% PEO-10 wt.\% GO-25 wt.\% $\mathrm{LiCF}_{3} \mathrm{SO}_{3}$ film with (ii) 0.2 wt.\% ES, (iii) 0.4 wt.\% ES, (iv) 1.0 wt.\% ES, and (v) 1.2 wt.\% ES in the region of $3400-3550 \mathrm{~cm}^{-1}$. (b) FTIR spectra of (i) 90 wt.\% PEO-10 wt.\% GO-25 wt.\% LiCF $\mathrm{SO}_{3}$ film with (ii) 0.2 wt.\% ES, (iii) 0.4 wt.\% ES, (iv) 0.6 wt.\% ES, (v) 0.8 wt.\% ES, (vi) 1.0 wt.\% ES, (vii) 1.2 wt.\% ES, and (vii) 1.4 wt. $\%$ ES in the region $1560-1760 \mathrm{~cm}^{-1}$.

room temperature is $(7.45 \pm 1.51) \times 10^{-11} \mathrm{~S} \mathrm{~cm}^{-1}$, which is relatively low since no mobile ions are provided within the film. On addition of 5 wt. $\% \mathrm{LiCF}_{3} \mathrm{SO}_{3}$, the conductivity increases to $(4.07 \pm 1.41) \times 10^{-9} \mathrm{~S} \mathrm{~cm}^{-1}$. The conductivity further increases to $(3.84 \pm 0.83) \times 10^{-6} \mathrm{~S} \mathrm{~cm}^{-1}$ on addition of 25 wt. $\% \mathrm{LiCF}_{3} \mathrm{SO}_{3}$. The conductivity of $\mathrm{PEO}-\mathrm{LiCF}_{3} \mathrm{SO}_{3}$ electrolyte is reported to be in the order of $\sim 10^{-6} \mathrm{~S} \mathrm{~cm}^{-1}[6,27$, $36]$. The conductivity decreases to $(6.25 \pm 1.03) \times 10^{-7} \mathrm{~S} \mathrm{~cm}^{-1}$ 


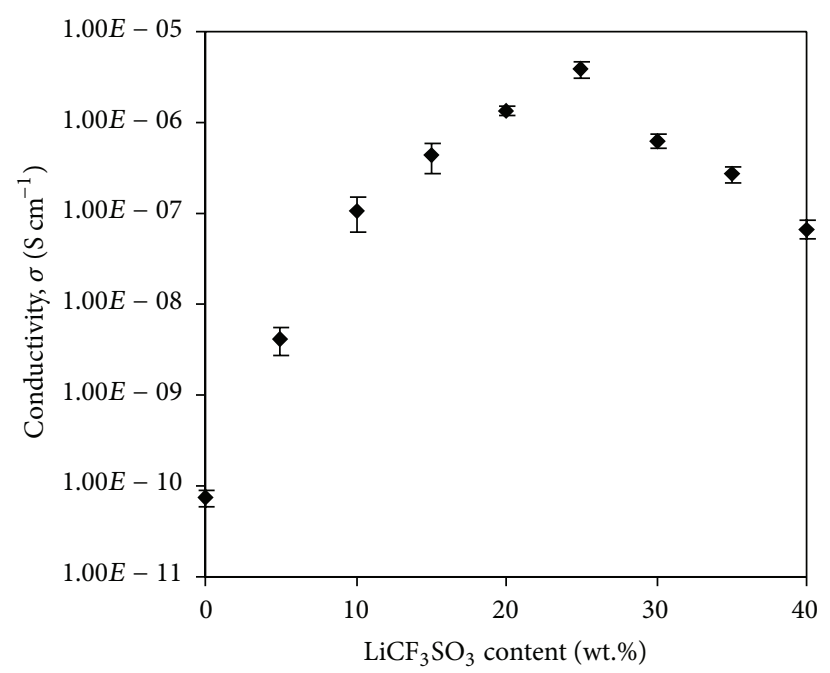

(a)

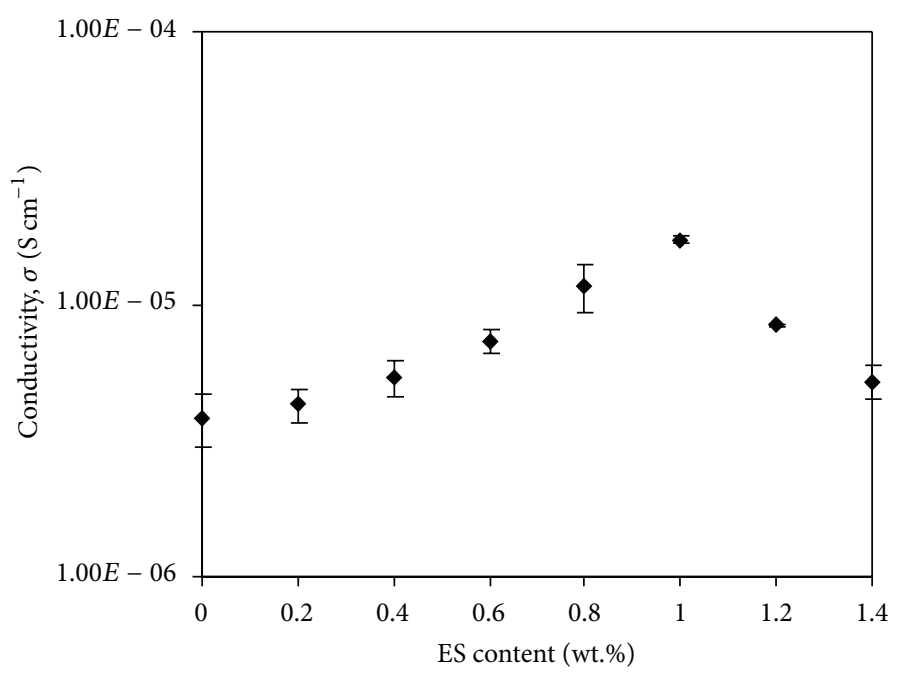

(b)

FIGURE 6: Room temperature conductivity as a function of (a) $\mathrm{LiCF}_{3} \mathrm{SO}_{3}$ content and (b) ES content.

with the addition of $30 \mathrm{wt} . \% \mathrm{LiCF}_{3} \mathrm{SO}_{3}$. The conductivity further decreases as salt concentration increases to $40 \mathrm{wt} . \%$. This phenomenon can be attributed to the influence of the ion pairs and higher ion aggregations, reducing the overall mobility and degree of freedom, hence decreasing the conductivity [37].

Apart from polymer blending, plasticization can also assist the conductivity enhancement by weakening the Columbic force between anions and cations of salt to promote salt dissociation. Since the $25 \mathrm{wt} . \% \mathrm{LiCF}_{3} \mathrm{SO}_{3}$ added electrolyte obtained the highest conductivity in salted system, the electrolyte was incorporated with different amounts of ES to enhance the conductivity. From Figure 6(b), the conductivity increases to $(1.73 \pm 0.51) \times 10^{-5} \mathrm{~S} \mathrm{~cm}^{-1}$ upon addition of $1 \mathrm{wt} \%$ ES. The incorporation of ES to the electrolyte assists the production of free mobile ions and lowered the viscosity of the electrolyte [38]. More free mobile ions are produced with addition of ES because the presence of plasticizer further weakens the Columbic force between cations and anions of the $\mathrm{LiCF}_{3} \mathrm{SO}_{3}$ salt, hence promoting more salts dissociation $[22,38,39]$. The use of ES in PEO-KOH films has been reported to increase the number density of mobile ions indicating that ES has dissociated more salts into ions and thus elevated the conductivity of SPE system [40]. The presence of plasticizer also creates alternative pathways for ions conduction which lead to conductivity enhancement [41]. This is because ES creates network formation through oxygen atoms in its molecules and thus increases the conductivity of the electrolyte system at room temperature.

3.4. Dielectric Studies. Dielectric study is useful in revealing the conductivity behavior of polymer electrolyte. This study gives an important insight into the polarization effect at the electrode/electrolyte interface and further understanding in conductivity trend [42]. The conductivity trend of the salted system and plasticized system of PEO-GO polymer host can be further verified by dielectric studies. Dielectric constant $\varepsilon_{r}$ is representative of stored charge in a material while dielectric loss $\varepsilon_{i}$ is a measure of energy losses to move ions when the polarity of electric field reverses rapidly $[43,44]$. The frequency dependence of $\varepsilon_{r}$ and $\varepsilon_{i}$ at room temperature for salted system (PEO-GO-LiCF $\mathrm{SO}_{3}$ ) and plasticized system (PEO-GO-LiCF $\mathrm{SO}_{3}$-ES) is shown in Figures $7(\mathrm{a})$ and $7(\mathrm{~b})$ and Figures 8(a) and 8(b), respectively. The equations for the dielectric constant $\varepsilon_{r}$ and dielectric loss $\varepsilon_{i}$ are as follows:

$$
\begin{aligned}
\varepsilon_{r} & =\frac{Z_{i}}{\omega C_{0}\left(Z_{r}^{2}+Z_{i}^{2}\right)} \\
\varepsilon_{i} & =\frac{Z_{r}}{\omega C_{0}\left(Z_{r}^{2}+Z_{i}^{2}\right)},
\end{aligned}
$$

where $Z_{r}$ and $Z_{i}$ are the real and imaginary parts of the impedance, $\omega$ is angular frequency, and $C_{0}$ is the vacuum capacitance. Based on the frequency dependence of real and imaginary parts of the $\varepsilon_{r}$ for both salted and plasticized system, there are no appreciable relaxation peaks observed in the frequency range use in this study. No relaxation peaks are observed signifying that the increase in conductivity is mainly due to the increase in number density of mobile ions [45]. The $\varepsilon_{r}$ rises sharply towards low frequencies for salted system and selected sample of plasticized system (Figure 7). This is due probably to the electrode polarization effects [46]. At high frequencies, the periodic reversal of the electric field occurs so fast that there is no excess ion diffusion in the direction of the field. The polarization due to the charge accumulation decreased, leading to the observed decrease in the value of $\varepsilon_{r}$ at high frequencies as reported by Ramesh et al. on PEO-LiCF $\mathrm{SO}_{3}$ system [6]. Based on Figure 8(a) of salted system, the higher value of dielectric loss $\varepsilon_{i}$ at low frequency is due to the free charge motion within material and also addition on the plasticizer $\varepsilon_{i}$ increases in the lower frequency region which reflects the enhancement of mobility charge carrier [47]. From Figure 8(b), $\varepsilon_{i}$ first decreases with rise in frequency in low frequency region followed by a peak in the loss spectra. The appearance of peak is attributed to the relaxation phenomena of polymer (motion of salt free 


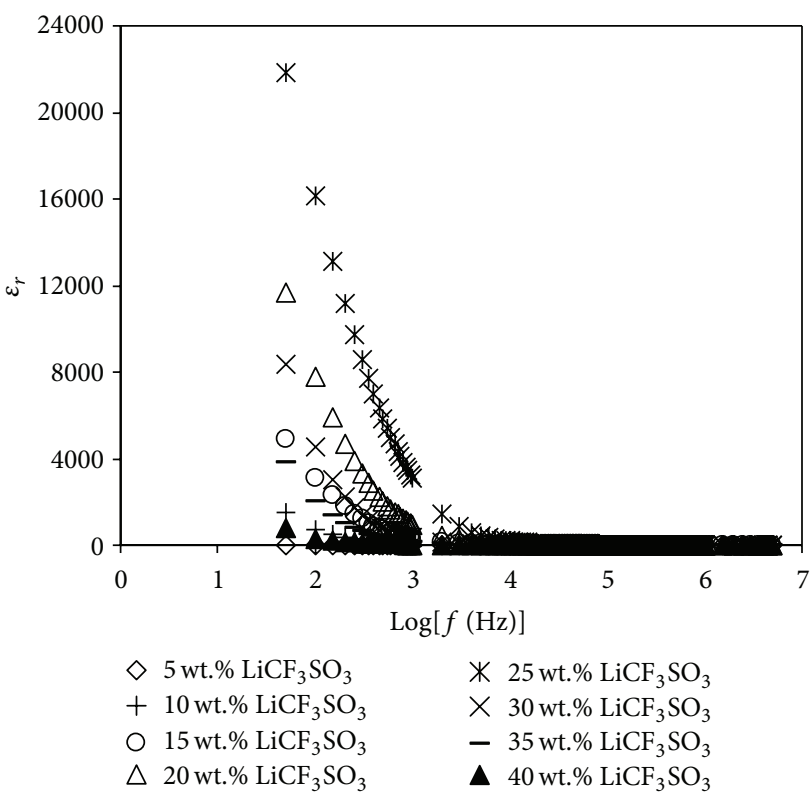

(a)

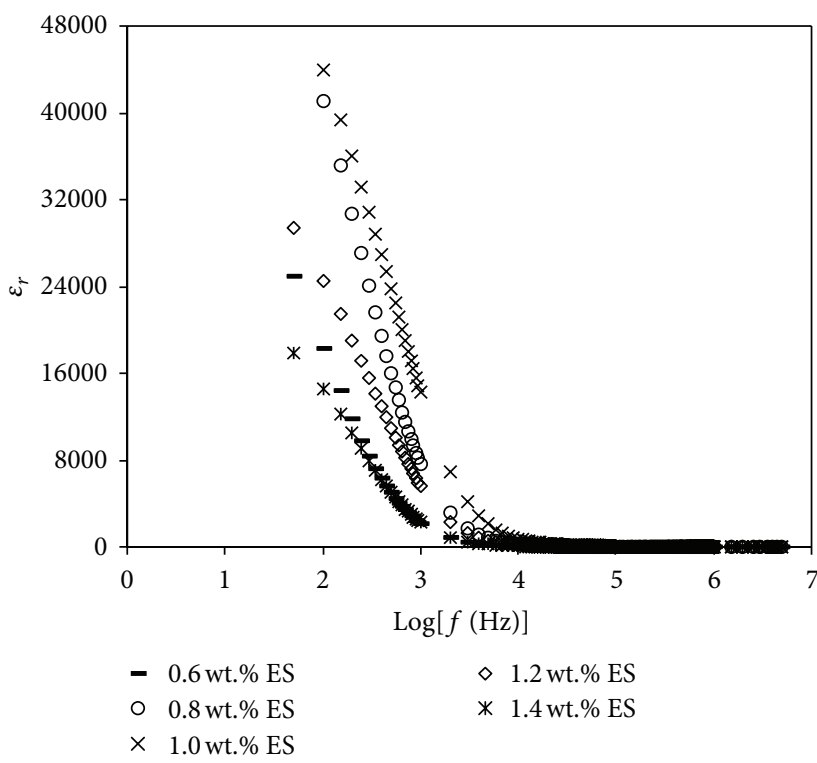

(b)

FIGURE 7: The frequency dependence of dielectric constant, $\varepsilon_{r}$, at room temperature: (a) salted system and (b) plasticized system for selected sample.

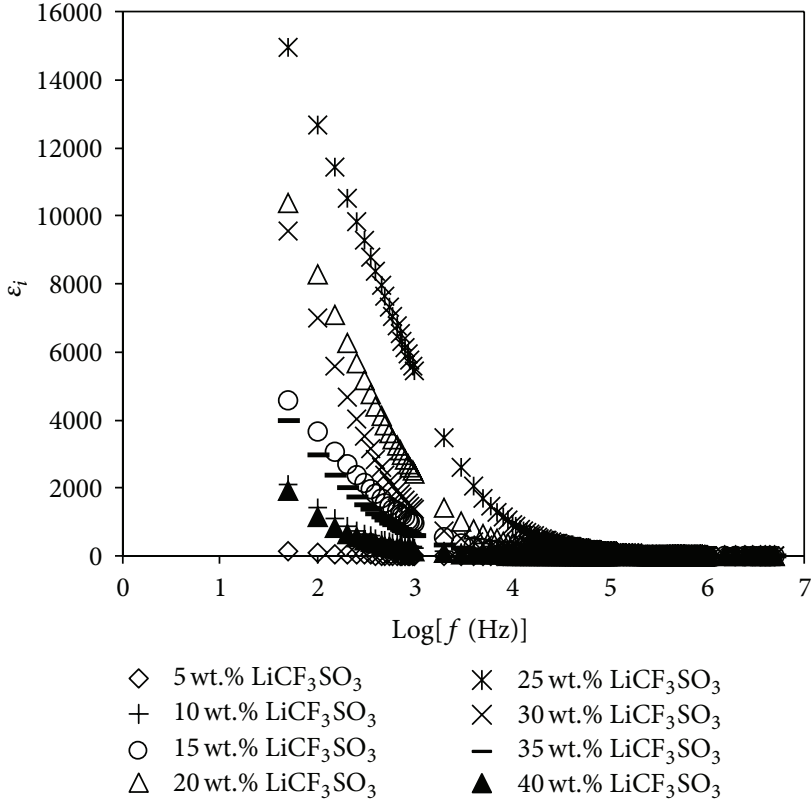

(a)

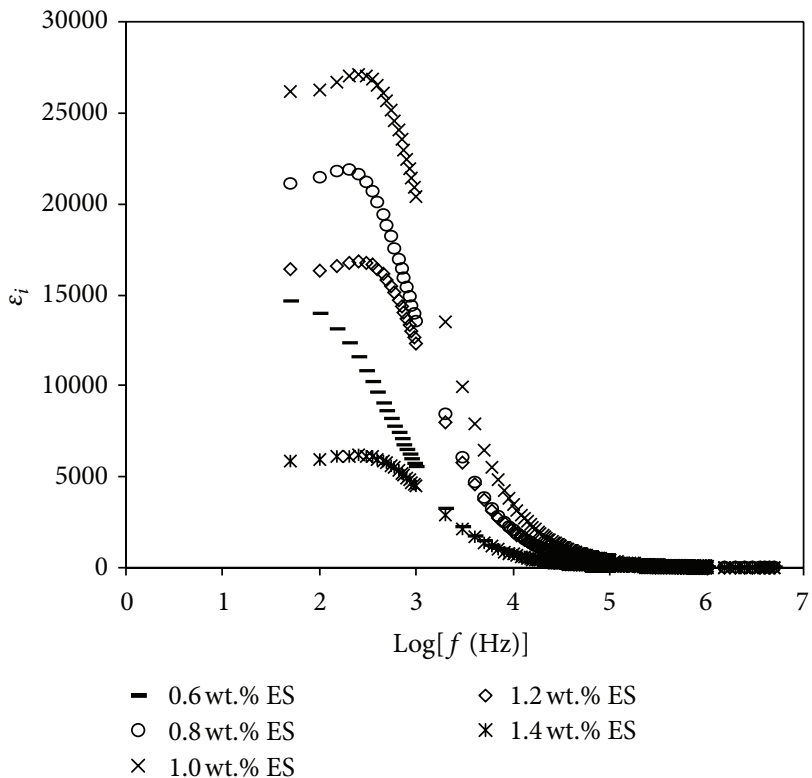

(b)

Figure 8: The frequency dependence of dielectric loss, $\varepsilon_{i}$, at room temperature: (a) salted system and (b) plasticized system for selected sample.

chain segment) [47]. Similar types of observations have been reported in the literature [45].

The plot of loss tangent $(\tan \delta)$ as a function of frequency can obtain the information of the relaxation phenomena. The value of $\tan \delta$ was calculated using

$$
\tan \delta=\frac{\varepsilon_{i}}{\varepsilon_{r}}
$$

The frequency dependence of $\tan \delta$ for selected electrolyte samples in salted and plasticized systems at room temperature is shown in Figures 9(a) and 9(b), respectively. The maximum of $\tan \delta\left(\tan \delta_{\max }\right)$, which represents the relaxation peak, is located at higher frequency for higher conducting electrolyte. The relaxation time $\left(t_{r}\right)$ for each electrolyte was obtained from the relation

$$
t_{r} \omega_{\text {peak }}=1 \text {, }
$$




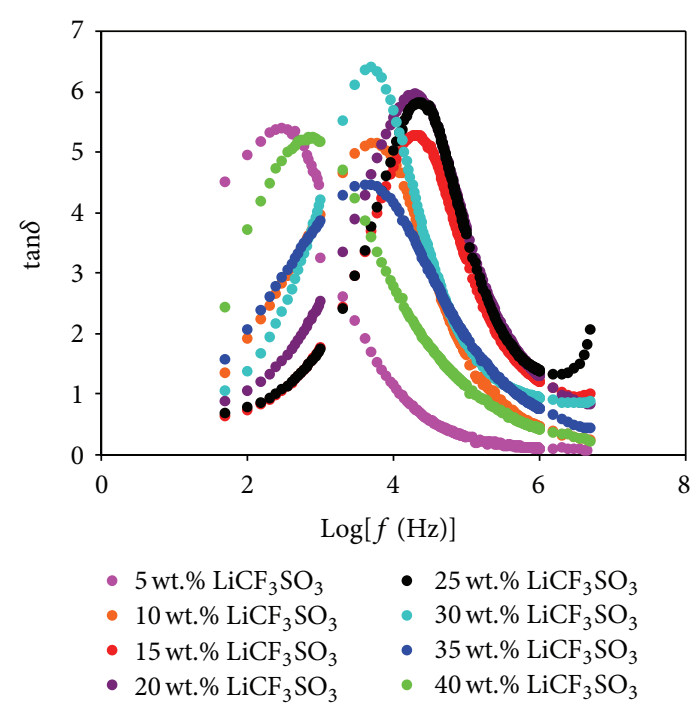

(a)

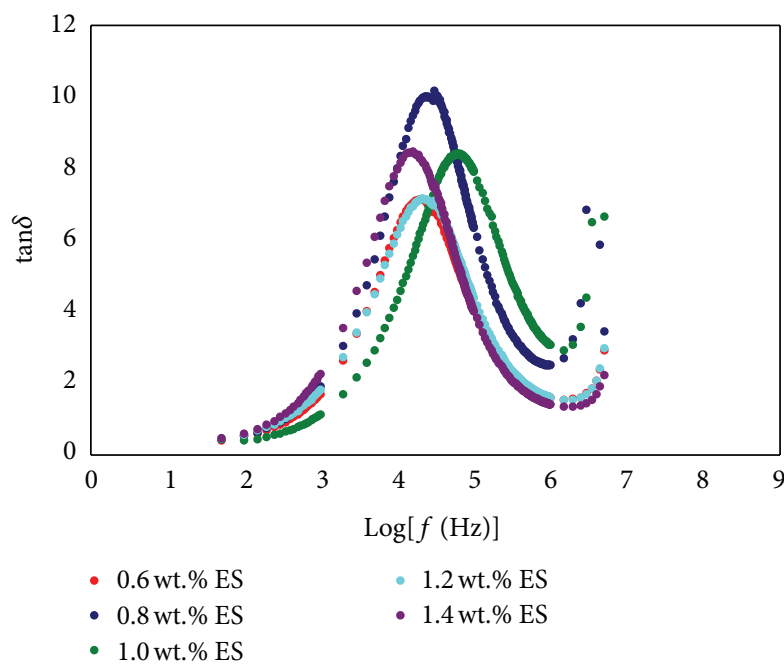

(b)

FIGURE 9: The frequency dependence of $\tan \delta$ at room temperature: (a) salted system and (b) plasticized system for selected sample.

TABLE 1: Relaxation time $\left(t_{r}\right)$ for PEO-GO-LiCF${ }_{3} \mathrm{SO}_{3}$ system.

\begin{tabular}{lc}
\hline $\mathrm{LiCF}_{3} \mathrm{SO}_{3}$ (wt.\%) & $t_{r}(\mathrm{~s})$ \\
\hline 5 & $4.55 \times 10^{-4}$ \\
10 & $3.18 \times 10^{-5}$ \\
15 & $7.95 \times 10^{-6}$ \\
20 & $8.37 \times 10^{-6}$ \\
25 & $7.23 \times 10^{-6}$ \\
30 & $3.18 \times 10^{-5}$ \\
35 & $3.98 \times 10^{-5}$ \\
40 & $1.98 \times 10^{-4}$ \\
\hline
\end{tabular}

where $\omega_{\text {peak }}$ is the angular frequency of the relaxation peak. The occurrence of relaxation time is the result of the efforts carried out by ionic charge carriers to obey the change in the direction of the applied field [48]. The values of $t_{r}$ for the salted system and selected samples of plasticized systems are shown in Tables 1 and 2, respectively. From Table 1, the highest conducting electrolyte with incorporation of $25 \mathrm{wt} . \%$ $\mathrm{LiCF}_{3} \mathrm{SO}_{3}$ possesses the lowest $t_{r}$ value of $7.23 \times 10^{-6} \mathrm{~s}$. In plasticized system, $t_{r}$ value is observed to decrease to 2.41 $\times 10^{-6} \mathrm{~s}$ as ES content increases to $1 \mathrm{wt} . \%$ as shown in Table 2. Other reports also show that the higher conducting electrolytes have the lower values of $t_{r}[48,49]$.

\section{Conclusion}

Electrolyte systems based on PEO-GO blend doped with $\mathrm{LiCF}_{3} \mathrm{SO}_{3}$ have been successfully prepared via solution cast technique. Based on the XRD results, the less crystallinity was obtained using 90 wt. $\%$ of PEO and 10 wt.\% of GO as polymer host. In salted system, highest conductivity of the PEO-GO blend polymer was achieved utilizing 25 wt. $\% \mathrm{LiCF}_{3} \mathrm{SO}_{3}$ with
TABLE 2: Relaxation time $\left(t_{r}\right)$ for PEO-GO-LiCF $\mathrm{SO}_{3}$-ES system.

\begin{tabular}{lc}
\hline ES (wt.\%) & $t_{r}(\mathrm{~s})$ \\
\hline 0.6 & $7.23 \times 10^{-6}$ \\
0.8 & $5.13 \times 10^{-6}$ \\
1 & $2.41 \times 10^{-6}$ \\
1.2 & $7.57 \times 10^{-6}$ \\
1.4 & $9.94 \times 10^{-6}$ \\
\hline
\end{tabular}

the value of $(3.84 \pm 0.83) \times 10^{-6} \mathrm{~S} \mathrm{~cm}^{-1}$ at room temperature. In plasticized system, the addition of $1.0 \mathrm{wt} . \% \mathrm{ES}$ has further enhanced the conductivity to $(1.73 \pm 0.51) \times 10^{-5} \mathrm{~S} \mathrm{~cm}^{-1}$. The relaxation time of the electrolytes is found to decrease with increasing conductivity at room temperature for both salted and plasticized system. From FTIR analysis, the complexation between the electrolyte components is proven by the shifting of $\mathrm{O}-\mathrm{H}$ band at $3000-3700 \mathrm{~cm}^{-1}, \mathrm{C}-\mathrm{H}$ stretch at $2800-$ $2900 \mathrm{~cm}^{-1}, \mathrm{CF}_{3}$ vibration at $600-700 \mathrm{~cm}^{-1}$, and $\mathrm{C}=\mathrm{O}$ band at $1500-1700 \mathrm{~cm}^{-1}$.

\section{Conflict of Interests}

The authors declare that there is no conflict of interests regarding the publication of this paper.

\section{Acknowledgment}

The authors thank the University of Malaya for the financial support (UMRG: RP010B-13AFR).

\section{References}

[1] M. B. Armand, J. M. Chabagno, and M. Duclot, "Poly-ethers as solid electrolytes," in Fast Ion Transport in Solids, P. Vashisha, J. 
N. Mundy, and G. K. Shenoy, Eds., p. 131, North Holland, New York, NY, USA, 1979.

[2] S. A. Hashmi, R. J. Latham, R. G. Linford, and W. S. Schlindwein, "Studies on all solid state electric double layer capacitors using proton and lithium ion conducting polymer electrolytes," Journal of the Chemical Society, Faraday Transactions, vol. 93, no. 23, pp. 4177-4182, 1997.

[3] G. S. MacGlashan, Y. G. Andreev, and P. G. Bruce, "Structure of the polymer eleotrolyte poly(ethylene oxide)6:LiAsF6," Nature, vol. 398, no. 6730, pp. 792-794, 1999.

[4] C. H. Manoratne, R. M. G. Rajapakse, and M. A. K. L. Dissanayake, "Ionic conductivity of poly(ethylene oxide) (PEO)montmorillonite (MMT) nanocomposites prepared by intercalation from aqueous medium," International Journal of Electrochemical Science, vol. 1, no. 1, pp. 32-46, 2006.

[5] M. Kumar and S. S. Sekhon, "Role of plasticizer's dielectric constant on conductivity modification of PEO-NH4F polymer electrolytes," European Polymer Journal, vol. 38, no. 7, pp. 12971304, 2002.

[6] S. Ramesh, T. F. Yuen, and C. J. Shen, "Conductivity and FTIR studies on PEO-LiX X : $\mathrm{CF}_{3} \mathrm{SO}_{3}^{-}, \mathrm{SO}_{2}^{-4}$ polymer electrolytes," Spectrochimica Acta Part A: Molecular and Biomolecular Spectroscopy, vol. 69, no. 2, pp. 670-675, 2008.

[7] K. Kesavan, C. M. Mathew, S. Rajendran, and M. Ulaganathan, "Preparation and characterization of novel solid polymer blend electrolytes based on poly (vinyl pyrrolidone) with various concentrations of lithium perchlorate," Materials Science and Engineering B: Solid-State Materials for Advanced Technology, vol. 184, no. 1, pp. 26-33, 2014.

[8] B. K. Money, K. Hariharan, and J. Swenson, "Relation between structural and conductivity relaxation in PEO and PEO based electrolytes," Solid State Ionics, vol. 262, pp. 785-789, 2014.

[9] E. Staunton, Y. G. Andreev, and P. G. Bruce, "Factors influencing the conductivity of crystalline polymer electrolytes," Faraday Discussions, vol. 134, pp. 143-156, 2007.

[10] E. Frackowiak and F. Béguin, "Carbon materials for the electrochemical storage of energy in capacitors," Carbon, vol. 39, no. 6, pp. 937-950, 2001.

[11] X. Li, X. Wang, L. Zhang, S. Lee, and H. Dai, "Chemically derived, ultrasmooth graphene nanoribbon semiconductors," Science, vol. 319, no. 5867, pp. 1229-1232, 2008.

[12] L. M. Viculis, J. J. Mack, O. M. Mayer, H. T. Hahn, and R. B. Kaner, "Intercalation and exfoliation routes to graphite nanoplatelets," Journal of Materials Chemistry, vol. 15, no. 9, pp. 974-978, 2005.

[13] G. Wang, B. Wang, J. Park, J. Yang, X. Shen, and J. Yao, "Synthesis of enhanced hydrophilic and hydrophobic graphene oxide nanosheets by a solvothermal method," Carbon, vol. 47, no. 1, pp. 68-72, 2009.

[14] W. E. Mahmoud, "Morphology and physical properties of poly(ethylene oxide) loaded graphene nanocomposites prepared by two different techniques," European Polymer Journal, vol. 47, no. 8, pp. 1534-1540, 2011.

[15] M. Cano, U. Khan, T. Sainsbury et al., "Improving the mechanical properties of graphene oxide based materials by covalent attachment of polymer chains," Carbon, vol. 52, pp. 363-371, 2013.

[16] A. K. Geim and K. S. Novoselov, “The rise of graphene," Nature Materials, vol. 6, no. 3, pp. 183-191, 2007.
[17] F. Croce, S. Sacchetti, and B. Scrosati, "Advanced, lithium batteries based on high-performance composite polymer electrolytes," Journal of Power Sources, vol. 162, no. 1, pp. 685-689, 2006.

[18] K. Vignarooban, M. A. K. L. Dissanayake, I. Albinsson, and B.E. Mellander, "Effect of $\mathrm{TiO}_{2}$ nano-filler and EC plasticizer on electrical and thermal properties of poly(ethylene oxide) (PEO) based solid polymer electrolytes," Solid State Ionics, vol. 266, pp. 25-28, 2014.

[19] M. R. Johan, O. H. Shy, S. Ibrahim, S. M. M. Yassin, and T. Y. Hui, "Effects of $\mathrm{Al}_{2} \mathrm{O}_{3}$ nanofiller and EC plasticizer on the ionic conductivity enhancement of solid PEO-LiCF $\mathrm{SO}_{3}$ solid polymer electrolyte," Solid State Ionics, vol. 196, no. 1, pp. 41-47, 2011.

[20] H. M. J. C. Pitawala, M. A. K. L. Dissanayake, and V. A. Seneviratne, "Combined effect of $\mathrm{Al}_{2} \mathrm{O}_{3}$ nano-fillers and EC plasticizer on ionic conductivity enhancement in the solid polymer electrolyte (PEO) ${ }_{9}$ LiTf," Solid State Ionics, vol. 178, no. 13-14, pp. 885-888, 2007.

[21] J. Syzdek, M. Armand, M. Marcinek, A. Zalewska, G. Zukowska, and W. Wieczorek, "Detailed studies on the fillers modification and their influence on composite, poly(oxyethylene)-based polymeric electrolytes," Electrochimica Acta, vol. 55, no. 4, pp. 1314-1322, 2010.

[22] M. F. Z. A. Kadir, M. F. Z. Abdul, L. P. Teo, S. R. Majid, and A. K. Arof, "Conductivity studies on plasticised PEO/chitosan proton conducting polymer electrolyte," Materials Research Innovations, vol. 13, no. 3, pp. 259-262, 2009.

[23] M. Ue, Y. Sasaki, Y. Tanaka, and M. Morita, "Nonaqueous electrolytes with advances in solvents," in Electrolytes for Lithium and Lithium-Ion Batteries, T. R. Jow, K. Xu, O. Borodin, and M. Ue, Eds., p. 148, Springer, New York, NY, USA, 2014.

[24] C. W. Lin, C. L. Hung, M. Venkateswarlu, and B. J. Hwang, "Influence of $\mathrm{TiO}_{2}$ nano-particles on the transport properties of composite polymer electrolyte for lithium-ion batteries," Journal of Power Sources, vol. 146, no. 1-2, pp. 397-401, 2005.

[25] W. S. Hummers Jr. and R. E. Offeman, "Preparation of graphitic oxide," Journal of the American Chemical Society, vol. 80, no. 6, p. $1339,1958$.

[26] K. K. Kumar, M. Ravi, Y. Pavani, S. Bhavani, A. K. Sharma, and V. V. R. Rao, "Investigations on PEO/PVP/NaBr complexed polymer blend electrolytes for electrochemical cell applications," Journal of Membrane Science, vol. 454, pp. 200-211, 2014.

[27] A. Asghar, Y. A. Samad, and R. Hashaikeh, "Cellulose/PEO blends with enhanced water absorption and retention functionality," Journal of Applied Polymer Science, vol. 125, no. 3, pp. 21212127, 2012.

[28] N. Reddeppa, T. J. R. Reddy, V. B. S. Achari, V. V. R. N. Rao, and A. K. Sharma, "Electrical and optical characterization of (PEO+PVAc) polyblend films," Ionics, vol. 15, no. 2, pp. 255-259, 2009.

[29] P. K. S. Mural, A. Banerjee, M. S. Rana et al., "Polyolefin based antibacterial membranes derived from PE/PEO blends compatibilized with amine terminated graphene oxide and maleated PE," Journal of Materials Chemistry A, vol. 2, no. 41, pp. 17635-17648, 2014.

[30] Y.-C. Cao, C. Xu, X. Wu, X. Wang, L. Xing, and K. Scott, "A poly (ethylene oxide)/graphene oxide electrolyte membrane for low temperature polymer fuel cells," Journal of Power Sources, vol. 196, no. 20, pp. 8377-8382, 2011. 
[31] S. R. Starkey and R. Frech, "Plasticizer interactions with polymer and salt in propylene carbonate-poly(acrylonitrile)-lithium triflate," Electrochimica Acta, vol. 42, no. 3, pp. 471-474, 1997.

[32] S. S. Sekhon, K. V. Pradeep, and S. A. Agnihotry, Solid State Ionics: Science and Technology, Edited by: B. V. R. Chowdari, K. Lal, S. A. Agnihotry, N. Khare, S. S. Sekhon, P. C. Srivastava, S. Chandra, World Scientific, Singapore, 1998.

[33] N. K. Karan, O. K. Pradhan, R. Thomas, B. Natesan, and R. S. Katiyar, "Solid polymer electrolytes based on polyethylene oxide and lithium trifluoro-methane sulfonate (PEO$\mathrm{LiCF}_{3} \mathrm{SO}_{3}$ ): ionic conductivity and dielectric relaxation," Solid State Ionics, vol. 179, no. 19-20, pp. 689-696, 2008.

[34] M. Yadav, K. Y. Rhee, and S. J. Park, "Synthesis and characterization of graphene oxide/carboxymethylcellulose/alginate composite blend films," Carbohydrate Polymers, vol. 110, pp. 1825, 2014.

[35] M. D. Bhatt and C. O'Dwyer, “The role of carbonate and sulfite additives in propylene carbonate-based electrolytes on the formation of SEI layers at graphitic Li-ion battery anodes," Journal of the Electrochemical Society, vol. 161, no. 9, pp. A1415A1421, 2014.

[36] H. M. J. C. Pitawala, M. A. K. L. Dissanayake, V. A. Seneviratne, B.-E. Mellander, and I. Albinson, "Effect of plasticizers (EC or $\mathrm{PC}$ ) on the ionic conductivity and thermal properties of the (PEO) ${ }_{9}$ LiTf: $\mathrm{Al}_{2} \mathrm{O}_{3}$ nanocomposite polymer electrolyte system," Journal of Solid State Electrochemistry, vol. 12, no. 7-8, pp. 783789, 2008.

[37] K. W. Chew and K. W. Tan, "The effects of ceramic fillers on PMMA-based polymer electrolyte salted with lithium triflate, $\mathrm{LiCF}_{3} \mathrm{SO}_{3}$," International Journal of Electrochemical Science, vol. 6, no. 11, pp. 5792-5801, 2011.

[38] M. F. Z. Kadir, S. R. Majid, and A. K. Arof, "Plasticized chitosan-PVA blend polymer electrolyte based proton battery," Electrochimica Acta, vol. 55, no. 4, pp. 1475-1482, 2010.

[39] M. F. Shukur, R. Ithnin, H. A. Illias, and M. F. Z. Kadir, "Proton conducting polymer electrolyte based on plasticized chitosanPEO blend and application in electrochemical devices," Optical Materials, vol. 35, no. 10, pp. 1834-1841, 2013.

[40] M. F. Hassan, N. H. Idris, S. R. Majid, T. Winie, A. S. A. Khiar, and A. K. Arof, "Effect of ethylene sulphite on the conductivity and morphology of PEO-KOH films," Materials Science Forum, vol. 517, pp. 89-92, 2006.

[41] A. Pawlicka, A. C. Sabadini, E. Raphael, and D. C. Dragunski, "Ionic thermogravimetry measurements of starch-based polymeric electrolytes," Molecular Crystal and Liquid Crystals, vol. 485, no. 1, pp. 804-816, 2008.

[42] M. C. Wintersgill, J. J. Fontanella, Y. S. Pak, S. G. Greenbaum, A. Al-Mudaris, and A. V. Chadwick, "Electrical conductivity, differential scanning calorimetry and nuclear magnetic resonance studies of amorphous poly(ethylene oxide) complexed with sodium salts," Polymer, vol. 30, no. 6, pp. 1123-1126, 1989.

[43] M. H. Buraidah, L. P. Teo, S. R. Majid, and A. K. Arof, "Ionic conductivity by correlated barrier hopping in $\mathrm{NH}_{4} \mathrm{I}$ doped chitosan solid electrolyte," Physica B: Condensed Matter, vol. 404, no. 8-11, pp. 1373-1379, 2009.

[44] H. J. Woo, S. R. Majid, and A. K. Arof, "Dielectric properties and morphology of polymer electrolyte based on poly $(\varepsilon$ caprolactone) and ammonium thiocyanate," Materials Chemistry and Physics, vol. 134, no. 2-3, pp. 755-761, 2012.
[45] M. Marzantowicz, J. R. Dygas, F. Krok, Z. Florjańczyk, and E. Zygadło-Monikowska, "Influence of crystallization on dielectric properties of PEO:LiTFSI polymer electrolyte," Journal of Non-Crystalline Solids, vol. 352, no. 42, pp. 5216-5223, 2006.

[46] R. Mishra and K. J. Rao, "Electrical conductivity studies of poly(ethyleneoxide)-poly(vinylalcohol) blends," Solid State Ionics, vol. 106, no. 1-2, pp. 113-127, 1998.

[47] D. K. Pradhan, R. N. P. Choudhary, and B. K. Samantaray, "Studies of dielectric relaxation and AC conductivity behavior of plasticized polymer nanocomposite electrolytes," International Journal of Electrochemical Science, vol. 3, no. 5, pp. 597-608, 2008.

[48] K. Ramly, M. I. N. Isa, and A. S. A. Khiar, "Conductivity and dielectric behaviour studies of starch/PEO+x wt- $\% \mathrm{NH}_{4} \mathrm{NO}_{3}$ polymer electrolyte," Materials Research Innovations, vol. 15, no. 2, pp. S82-S85, 2011.

[49] N. H. Idris, H. B. Senin, and A. K. Arof, "Dielectric spectra of LiTFSI-doped chitosan/PEO blends," Ionics, vol. 13, no. 4, pp. 213-217, 2007. 

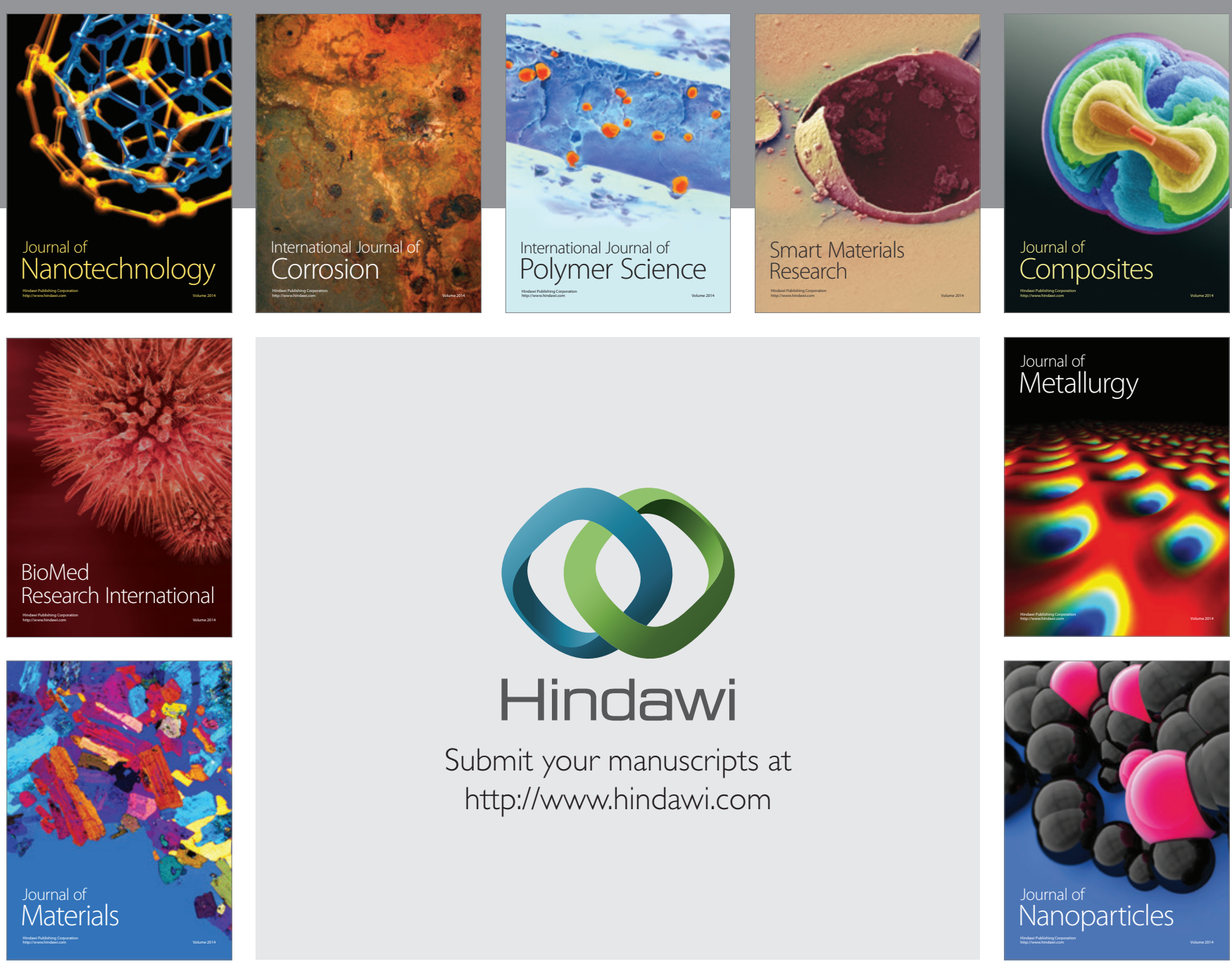

Submit your manuscripts at http://www.hindawi.com
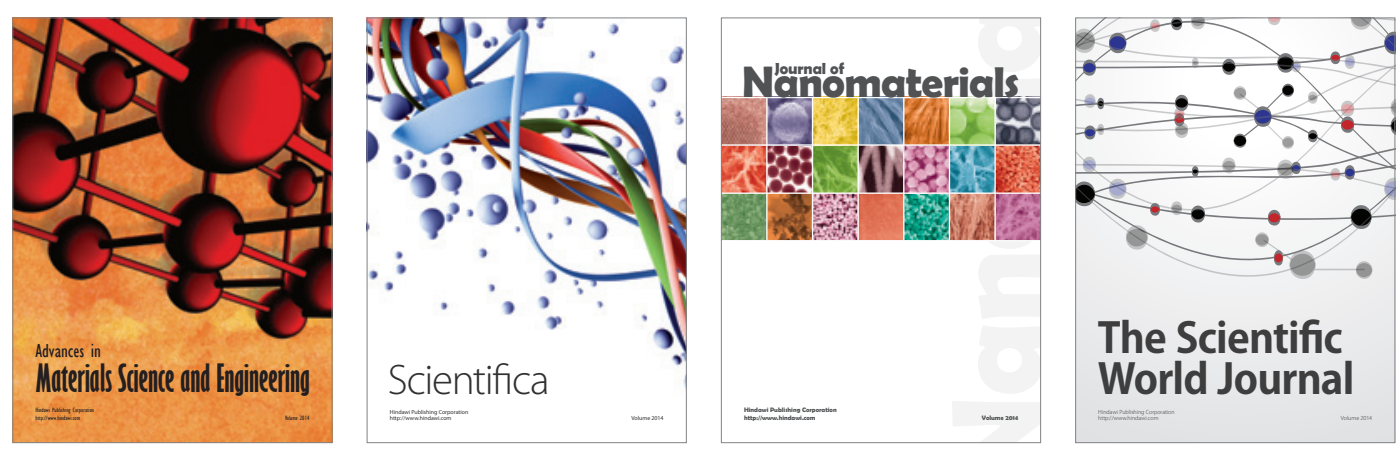

\section{The Scientific World Journal}
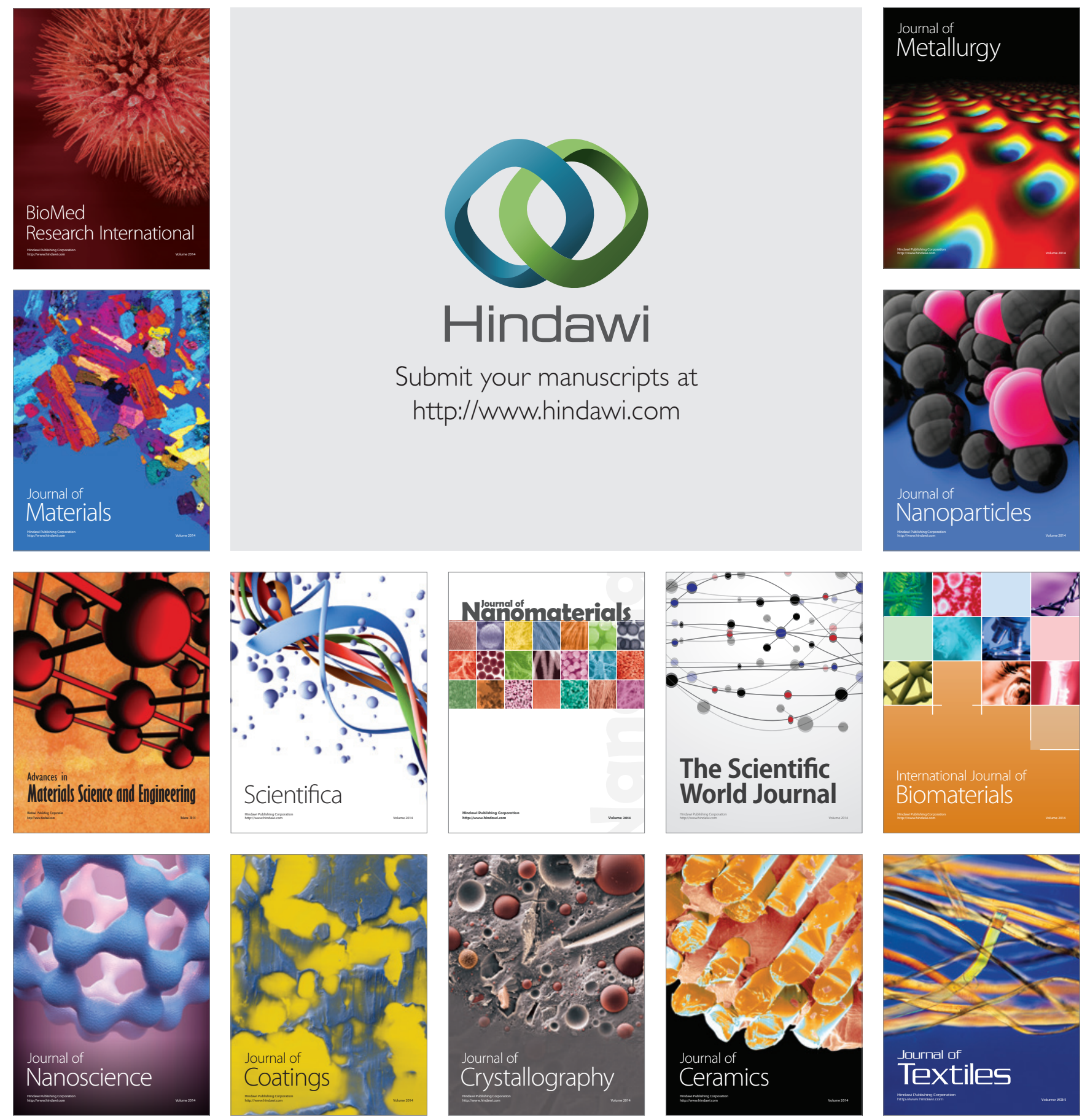